\title{
A Case Study on Performance and Safety Test of Defibrillator Devices
}

\author{
Ali Tavakoli Golpaygani ${ }^{1}$ and Mohammad Mehdi Movahedi ${ }^{2, *}$ \\ ${ }^{1}$ Department of Biomedical Engineering, Standard Research Institute, Karaj, Iran \\ ${ }^{2}$ Department of Medical Physics, School of Medicine, Shiraz University of Medical Sciences, Shiraz, Iran \\ ${ }^{*}$ Corresponding author
}

\begin{abstract}
Nowadays more than 10,000 different types of medical devices can be found in hospitals. In this way, medical electrical equipment is being employed in a wide variety of fields in medical sciences with different physiological effects and measurements. Hospitals and medical centers must ensure that their critical medical devices are safe, accurate, reliable and operating at the required level of performance. Defibrillators are critical resuscitation devices. The use of reliable defibirillators has led to more effective treatments and improved patient safety through better control and management of complications during Cardiopulmonary resuscitation (CPR). The metrological reliability of twenty (20) frequent uses, manual defibrillators in use ten hospitals (4 privates and 6 publics) in one province according to international and national standards was evaluated. Quantitative analysis of controls and instruments accuracy, showed the amount of the obtained results in many units are critical and have less value over the standard limitations especially in devices with poor battery. Acquiring results indicate a need for new and severe regulations on periodic performance verifications and medical equipment quality control program especially in high risk instruments. It is also necessary provide training courses on the fundumental of operation and performane parameters for medical staff in the field of meterology in medicine and how can get good accuracy results especially in high risk medical devices.
\end{abstract}

Keywords-meterology; defebrillator; electroshock; patient safety; medical electrical devices

\section{INTRODUCTION}

Medical research and statistical analysis all over the world show generally over 135 ; 000 people die annually following acute myocardial infarction as ventricular fibrillation (VF) or ventricular tachycardia (VT); and the only effective treatment for which is early defibrillation. Defibrillation consists of delivering a therapeutic dose of electrical energy with a device called defibrillator to the affected heart. Defibrillation is the application of a predefine electrical current across the myocardium to cause synchronous depolarization of the cardiac muscle; this action terminates the arrhythmia; and allows normal sinus rhythm to be reestablished. In 1899; Prevost and Batelli; two physiologists from University of Geneva; demonstrated small electric shocks could induce ventricular fibrillation in dogs and the larger charges would reverse the condition. The defibrillator was invented in 1932 by $\mathrm{Dr}$ William Bennett Kouwenhoven and the first use on a human was in 1947 by Claude Beck. In 1959 Bernard Lown commenced research into an alternative technique which involved charging of a bank of capacitors and then delivering the charge through an inductance to the heart by way of 'paddle' electrodes. The work of Lown was taken to clinical application by engineer Barouh Berkovits with his "cardioverter". The Lown waveform was the standard for defibrillation until the late 1980s when numerous studies showed that a biphasic truncated waveform (BTE) was equally efficacious while requiring the delivery of lower levels of energy to produce defibrillation with less hazards and side effect. [1;2].

Early defibrillation is critical to survival from cardiac arrest for several reasons: (1) the most frequent initial rhythm in witnessed sudden cardiac arrest is VF; (2) the most effective treatment for VF is electrical defibrillation; (3) the probability of successful defibrillation diminishes rapidly over time; and (4) VF tends to convert to asystole within a few minutes. The chance of a successful treatment decline at a rate of about $10 \%$ for each minute cardiac defibrillation is delayed.

So; a complete understanding of defibrillator classification; mechanism of action; preparation and techniques for defibrillation is critical in reducing potential complications and hazards. Also; it must be regularly the performance and safety of these devices verified at least annually by using adequate analyzer via expert persons. Particularly; for defibrillator equipment type approval involves compliance with these standards; a) IEC 60601-1 (Medical Electrical Equipment Part1: General requirements for safety); b) The particular standard IEC 60601-2-4 (Medical Electrical Equipment - Part2: Particular requirements for the basic safety and essential performance of cardiac defibrillators) and or c) national standards $[2 ; 3]$.

In order to access the requirement of periodic verifications; the metrological reliability of defibrillators which are in use at healthcare centers should be evaluated. For this purpose; in this research; twenty (20) defibrillators were used at ten hospitals and clinics; six publics and four privates; in one of Iran's province were evaluated and tested under some of the relevant safety and performance parameters.

\section{TECHNICAL BACKGROUND}

\section{A. Principles of Defibrillator}

A typical defibrillator includes a power supply; capacitor; inductor; variable transformer and rectifier. Figure 1 shows a simple circuit of a defibrillator. The power source can come from a battery or the mains supply. 
Capacitor is the most important component of a defibrillator that stores a large amount of electrical charge; then releases it over a short period of time in patient's heart. Effective defibrillation depends on released energy at the heart. The current and charge delivered by a discharging capacitor decay rapidly in exponential function. The current delivered must be maintained in several milliseconds for a successful defibrillation. The inductor minimizes the rapid decay of current flow (delivered energy); it prolongs the duration of current flow to allow for optimum time.

An adjustable transformer is used to convert the mains voltage of $240 \mathrm{~V} \mathrm{AC}$ to $5000 \mathrm{~V}$ AC. By a rectifier; this is then converted to $5000 \mathrm{~V}$ DC. In practice; a variable voltage step-up transformer for selecting the different amounts of adequate charge is used by physician $[4 ; 5]$.

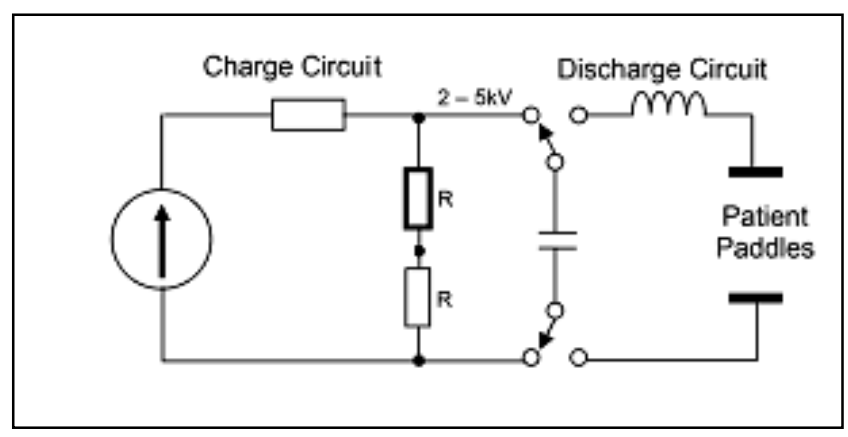

FIGURE I. A SIMPLE CIRCUIT OF A DEFIBRILLATOR

\section{B. Types of Defibrillators}

Several types of defibrillators are used to correct abnormal and life threatening heart rhythms. Defibrillators categorized to external; transvenous; or implanted depending on the type of device used or needed. [4; 5].

Some of these types are mention below.

a) Manual external defibrillator;

b) Manual internal defibrillator;

c) Automated external defibrillator (AED);

d) Implantable cardioverter-defibrillator (ICD);

e) Wearable cardiac defibrillator.

\section{MATERIALS AND METHODS}

In this study twenty defibrillators; five (5) different brands were used at ten (10) hospitals; six publics and four privates were tested. The technical history of each unit was not informed or not completed by the hospitals; however they announced that none of the unit analyzed had been acquired recently.

The setup that was used for the accuracy of controls and instruments measurements was designed in accordance with the particular safety standard IEC 60601-2-4. Delivered energy were measured with a Neteck Biomedical Analyzer (DELTA 3000) and a Fluke Electrical Safety Analyzer (ESA 620) used for general electrical safety evaluations for measuring the patient leakage current and patient auxiliary leakage current; $[5 ; 6]$.

\section{A. Performance Parameters}

There are several parameters that impact the performance of defibrillators devices. Some of these parameters are demonstrated at table $(1) ;[6 ; 7]$.

TABLE I. PERFORMANCE PARAMETERS OF DEFIBRILLATORS EQUIPMENT

\begin{tabular}{|c|c|}
\hline Qualitative Tasks & Quantitative Tasks \\
\hline Chassis/Housing & Accuracy of controls and instruments \\
\hline Strain Reliefs & Charging time \\
\hline Paddles/Electrodes & Internal electrical power source \\
\hline Fitting/Connectors & SYNCHRONIZER \\
\hline Controls/Switches & Device operation after battery Alarm \\
\hline Indicators/Displays & Batteries \\
\hline Alarm/Audible Signals & Energy waveform \\
\hline Battery/Charger & Electrical Safety Tests \\
\hline
\end{tabular}

Ideally; all safety and performance parameters should have been evaluated; but as emergency situation of these devices in medical centers; therefore the number of performed tests were limited and only the critical parameters have been considered.

According to the particular safety standard IEC 60601-2-4; accuracy of delivered energy should be performed in different simulated impedances $(25 \Omega ; 50 \Omega ; 75 \Omega ; 100 \Omega ; 125 \Omega ; 150$ $\Omega$ and $175 \Omega$ ). So; the test was performed for maximum output delivered energy in three different loads $25 ; 50$ and $100 \Omega$ and the other selected energy in $50 \Omega$. In order to prevent unintended interrupt in actual emergency situation; it is necessary; all of the evaluation process carried out based on battery mode.

Several of the safety tests according to general standard for medical electrical equipment (IEC 60601-1); especially patient leakage current and patient auxiliary leakage current; were performed in all defibrillator devices; [6;7].

\section{RESULTS AND DisCUSSION}

The performance and safety testing of frequent use; manual defibrillators equipment in use at ten hospitals was evaluated. Table (2) shows a brief history of achieved results at maximum setting level.

Quantitative analysis of accuracy of delivered energy measurements; showed the amount of the obtained results in many units is critical and have less value over the standard limitations; especially in devices with poor battery. The delivered energy of defibrillators especialy in frequent discharge is dependent seriously on the power battery condition.

For the accuracy of delivered energy analysis (table 2); only twelve units delivered acceptable output values and the precision in the output energy measurements especialy in poor battry condition; after activation of discharge alarm were low.

General electrical safety evaluations for measuring the patient leakage current and patient auxiliary leakage current carried out for all of the under test devices. In some cases the amount of leakage currents were over the standard limitations. As a technical investigation; it is shown that the earth system 
quality of hospital has a rol key in electrical safety test and it is necessary to evaluate the quality of hospital earth system.

\section{CONCLUSION}

Defibrillators are critical resuscitation devices. Their failure to perform effectively may result in the death of a patient undergoing resuscitation or cause further cardiac damage or even death in a patient undergoing cardioversion of a lifethreatening arrhythmia. The use of defibirillators has led to more effective treatments and improved patient safety through better control and management of complications during Cardiopulmonary resuscitation (CPR).

Acquiring results indicate a need for new and severe regulations on periodic performance verifications and medical equipment quality control program especially in high risk instruments. It is also necessary provide training courses on the fundumental of operation and performane parameters for medical staff in the field of meterology in medicine and how can get good accuracy results especially in high risk medical devices.

\section{ACKNOWLEDGMENT}

This research was supported by Standard Research Institute. We thank our colleagues in Persia Azma Company who provided insight and expertise that greatly assisted the research; especially in analysis performance.

\section{REFERENCES}

[1] Trayanova N. (2005) " Defibrillation of the heart: insights into mechanisms from modelling studies". Experimental Physiology 91(2):323-337

[2] Hutton P.; Cooper G. M.; Butterworth J. F. "Fundamental principles and practice of anaesthesia". London; 2002.

[3] Gad S. C. "Safety Evaluation of Medical Devices". Marcel Dekker; 2002

[4] Khandpour R. S. "Handbook of Biomedical Instrumentation". Mc Graw Hill; 2014

[5] Street L. "Introduction to Biomedical Engineering technology". CRC Press; 2008.

[6] International Electrotechnical Commission. IEC 60601-1-1; Medical Electrical Equipment- Part1: General requirements for Safety1: Collateral Standard: Safety Requirements for Medical electrical Systems.

[7] International Electrotechnical Commission. IEC 60601-2-4; Medical electrical equipment - Part 2-4: Particular requirements for the basic safety and essential performance of cardiac defibrillators.

TABLE II. A BRIEF SUMMARY OF EVALUATED TECHNICAL RESULT FOR EACH UNIT (UNITS ARE FREQUENT USE; MANUAL DEFIBRILLATORS)

\begin{tabular}{|c|c|c|c|c|c|c|c|c|c|c|c|c|c|c|c|c|c|c|c|c|c|}
\hline \multicolumn{2}{|c|}{ Items } & U1 & $\mathrm{U} 2$ & U3 & U4 & U5 & U6 & U7 & U8 & U9 & U 10 & U11 & $\begin{array}{c}\mathrm{U} 1 \\
2 \\
\end{array}$ & $\begin{array}{c}\mathrm{U} 1 \\
3 \\
\end{array}$ & $\begin{array}{c}\mathrm{U} 1 \\
4 \\
\end{array}$ & $\begin{array}{c}\mathrm{U} 1 \\
5 \\
\end{array}$ & U16 & $\begin{array}{c}\mathrm{U} 1 \\
7 \\
\end{array}$ & U 18 & U19 & $\begin{array}{c}\mathrm{U} 2 \\
0 \\
\end{array}$ \\
\hline \multicolumn{2}{|c|}{ Energy Waveform } & $\sqrt{ }$ & $\sqrt{ }$ & $\sqrt{ }$ & * & $\sqrt{ }$ & $*$ & $\sqrt{ }$ & $*$ & $\sqrt{ }$ & $x$ & $\sqrt{ }$ & $\sqrt{ }$ & $\sqrt{ }$ & $x$ & $\sqrt{ }$ & $x$ & $\sqrt{ }$ & $x$ & $\sqrt{ }$ & $x$ \\
\hline \multicolumn{2}{|c|}{$\mathrm{CT}$} & $\sqrt{ }$ & $\sqrt{ }$ & $\sqrt{ }$ & $x$ & $\sqrt{ }$ & $x$ & $\sqrt{ }$ & $x$ & $\sqrt{ }$ & $x$ & $\sqrt{ }$ & $\sqrt{ }$ & $\sqrt{ }$ & $x$ & $\sqrt{ }$ & $x$ & $\sqrt{ }$ & $x$ & $\sqrt{ }$ & $x$ \\
\hline \multicolumn{2}{|c|}{ SYNC. } & $\sqrt{ }$ & $\sqrt{ }$ & $\sqrt{ }$ & $\sqrt{ }$ & $\sqrt{ }$ & $\sqrt{ }$ & $\sqrt{ }$ & $\sqrt{ }$ & $\sqrt{ }$ & $\sqrt{ }$ & $\sqrt{ }$ & $\sqrt{ }$ & $\sqrt{ }$ & $\sqrt{ }$ & $\sqrt{ }$ & $\sqrt{ }$ & $\sqrt{ }$ & $\sqrt{ }$ & $\sqrt{ }$ & $\sqrt{ }$ \\
\hline \multicolumn{2}{|c|}{ Battery } & $\sqrt{ }$ & $\sqrt{ }$ & $\sqrt{ }$ & $x$ & $\sqrt{ }$ & $x$ & $\sqrt{ }$ & $\times$ & $\sqrt{ }$ & $x$ & $\sqrt{ }$ & $\sqrt{ }$ & $\sqrt{ }$ & $x$ & $\sqrt{ }$ & $x$ & $\sqrt{ }$ & $\times$ & $\sqrt{ }$ & $x$ \\
\hline \multicolumn{2}{|c|}{$\mathrm{DE}$} & $* *$ & $*$ & $*$ & $* *$ & $*$ & $* *$ & $*$ & $* *$ & $*$ & $* *$ & $*$ & $*$ & $*$ & $* *$ & $*$ & $* * *$ & $* *$ & $* * *$ & $*$ & $\begin{array}{c}* * \\
*\end{array}$ \\
\hline \multirow[b]{2}{*}{ ENRGY } & $\mathrm{E}(\mathrm{A})$ & $*$ & $*$ & * & $* *$ & $*$ & $* *$ & $*$ & $* *$ & $*$ & $* *$ & $*$ & * & $*$ & $* *$ & $*$ & $* *$ & $*$ & $* *$ & $*$ & $\begin{array}{c}* * \\
*\end{array}$ \\
\hline & $\mathrm{E}(\mathrm{B})$ & $*$ & $*$ & $*$ & $* *$ & $*$ & $* *$ & $*$ & $* *$ & $*$ & $* *$ & $*$ & $*$ & $*$ & $* *$ & $*$ & $* *$ & $*$ & $* * *$ & $*$ & $\begin{array}{c}* * \\
*\end{array}$ \\
\hline \multicolumn{2}{|c|}{$\begin{array}{c}\text { Patient Leakage } \\
\text { Current }\end{array}$} & $\sqrt{ }$ & $\sqrt{ }$ & $\sqrt{ }$ & $x$ & $\sqrt{ }$ & $\sqrt{ }$ & $\sqrt{ }$ & $\times$ & $\sqrt{ }$ & $\sqrt{ }$ & $\sqrt{ }$ & $\sqrt{ }$ & $\sqrt{ }$ & $x$ & $\sqrt{ }$ & $\times$ & $\sqrt{ }$ & $x$ & $\sqrt{ }$ & $\times$ \\
\hline \multicolumn{2}{|c|}{$\begin{array}{l}\text { Patient Auxillary } \\
\text { Leakage Current }\end{array}$} & $\sqrt{ }$ & $\sqrt{ }$ & $\sqrt{ }$ & $\times$ & $\sqrt{ }$ & $\sqrt{ }$ & $\sqrt{ }$ & $\times$ & $\sqrt{ }$ & $x$ & $\sqrt{ }$ & $\sqrt{ }$ & $\sqrt{ }$ & $x$ & $\sqrt{ }$ & $\times$ & $\sqrt{ }$ & $x$ & $\sqrt{ }$ & $\times$ \\
\hline \multicolumn{10}{|c|}{$\mathrm{E}(\mathrm{A})$ : Accuracy of Delivered Energy in $50 \Omega$ load } & \multicolumn{12}{|c|}{ E(B): Accuracy of Delivered Energy in different loads } \\
\hline \multicolumn{6}{|c|}{$* 5-15 \%$} & \multicolumn{8}{|c|}{$* * \quad 15-30 \%$} & \multicolumn{8}{|c|}{$* * *$ Above $30 \%$} \\
\hline \multicolumn{7}{|c|}{$\begin{array}{c}\text { CT:for Frequent Use; Manual } \\
\text { Defibillators ; Time Charging after } 15 \text { Sequential } \\
\text { Discharge } \leq 15 \mathrm{~s}\end{array}$} & \multicolumn{5}{|c|}{$\begin{array}{c}\text { Patient Auxillary Leakage } \\
\text { Current } \\
\text { Normal Condition } \\
\text { CF Type: } 10 \mu \mathrm{A} \\
\text { BF Type: } 100 \mu \mathrm{A}\end{array}$} & \multicolumn{5}{|c|}{$\begin{array}{c}\text { Patient Auxillary Leakage } \\
\text { Current } \\
\text { Fault Condition } \\
\text { CF Type: } 50 \mu \mathrm{A} \\
\text { BF Type: } 500 \mu \mathrm{A} \\
\end{array}$} & \multicolumn{5}{|c|}{$\begin{array}{l}\text { DE: Delivered Energy after } \\
\text { Discharge Alarm }\end{array}$} \\
\hline \multicolumn{7}{|c|}{ SYNC: Syncronization Operation } & \multirow{2}{*}{\multicolumn{5}{|c|}{$\begin{array}{l}\text { Patient Leakage Current } \\
\text { Normal Condition } \\
\text { CF Type: } 10 \mu \mathrm{A} \\
\text { Bf Type: } 100 \mu \mathrm{A}\end{array}$}} & \multirow{2}{*}{\multicolumn{5}{|c|}{$\begin{array}{c}\text { Patient Leakage Current } \\
\text { Fault Condition } \\
\text { CF Type: } 50 \mu \mathrm{A} \\
\text { BF Type: } 500 \mu \mathrm{A}\end{array}$}} & \multicolumn{5}{|c|}{$\sqrt{ }-$ In Standard Limitation } \\
\hline \multicolumn{2}{|c|}{$\begin{array}{c}\text { NA: Not } \\
\text { Applicable }\end{array}$} & \multicolumn{5}{|c|}{ NP: Not Performed } & & & & & & & & & & & \multicolumn{5}{|c|}{$x$ - Out of Standard Limitation } \\
\hline
\end{tabular}

